\title{
Risk factors for childhood obesity in a Greek paediatric population
}

\author{
Dimitrios Papandreou ${ }^{1, *}$, Pavlos Malindretos ${ }^{2}$ and Israel Rousso ${ }^{1}$ \\ ${ }^{1}$ Second Department of Pediatrics, Aristotle University of Thessaloniki, School of Medicine, Ahepa General \\ Hospital, St. Kiriakidi 1, TK 54636, Greece: ${ }^{2}$ Nephrology Department, General Hospital of Volos, \\ Volos, Greece
}

Submitted 13 July 2009: Accepted 30 November 2009: First published online 15 January 2010

\begin{abstract}
Objective: Obesity in children is a serious public health issue in Greece. The purpose of the current study was to identify risk factors such as birth weight, breast-feeding, dietary patterns, family history of obesity and sedentary behaviours that are possibly associated with paediatric obesity.

Design: Two hundred and five overweight and obese children (OW/OB; group 1) aged $7-15$ years from eight primary and secondary schools and a control group (group 2) of normal-weight children were matched for age and sex. Overweight and obesity were calculated based on the International Obesity Taskforce criteria. Lifestyle parameters as well as anthropometric data were collected in all children. Conditional logistic regression analysis was used to identify risk factors for obesity. Results: Breast-feeding ( $\geq 3$ months) and leisure-time physical activity proved to be protector factors against obesity $(\mathrm{OR}=0 \cdot 21,95 \% \mathrm{CI} 0 \cdot 11,0 \cdot 79, P<0 \cdot 001$ and $\mathrm{OR}=0 \cdot 87,95 \% \mathrm{CI} 0 \cdot 85,0 \cdot 89, P<0 \cdot 001$ respectively). On the other hand, family history of obesity (OR $=3 \cdot 79,95 \%$ CI $2 \cdot 61,4 \cdot 18, P<0 \cdot 001)$, sugar-sweetened beverage consumption ( $\mathrm{OR}=1 \cdot 77,95 \% \mathrm{CI} 1 \cdot 03,2 \cdot 76, P<0 \cdot 001)$ and watching television ( $\mathrm{OR}=1.99,95 \% \mathrm{CI} 1 \cdot 54,2 \cdot 76, P=0 \cdot 04)$ were found to be positively associated with a higher obesity risk.

Conclusions: The current findings support the literature according to which duration of breast-feeding ( $<3$ months), a family history of obesity, watching television, sedentary lifestyle and consumption of sugar-sweetened beverages are important risk factors for childhood obesity. More studies are needed to elucidate the relationship of paediatric obesity and possible predictor factors in order to avoid health consequences in these children later on in life.
\end{abstract}

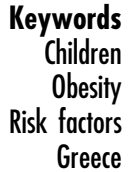

Keywords

Children

factors

Greece
The prevalence of childhood obesity is rising at an alarming rate worldwide ${ }^{(1)}$. Paediatric obesity is a serious health issue problem that is increasing dramatically in Greece ${ }^{(2,3)}$

The prevalence of paediatric obesity in Greece is very high $^{(2,4)}$. Several studies in Greece have found an association of obesity with different risk factors. Malindretos et $a l .{ }^{(5)}$ reported that parental obesity may increase the risk of obesity in their children by $40 \%$. Linardakis et al. ${ }^{(6)}$ found that high intake of sugar-sweetened beverages was associated with an increased risk of childhood obesity. Sedentary behaviours as well as watching television were found to be significantly correlated with obesity in 198 children from Volos $^{(7)}$. Duration of breast-feeding ( $\geq 3$ months) has been controversial as far as childhood obesity is concerned ${ }^{(8,9)}$. In a recent study in 2374 Greek children, breast-feeding was found to be a protective factor against childhood obesity ${ }^{(10)}$.
CVD in adults is the leading cause of deaths in Greece $^{(11)}$. Health problems such as hypertension, diabetes type 2 and dyslipidaemia have been found to be established at young ages in Greek paediatric populations ${ }^{(7,12)}$. A number of recent studies have suggested that childhood obesity in most cases tracks into adulthood ${ }^{(13)}$ and increases the risk of degenerative diseases later in life ${ }^{(14)}$. In common with adulthood obesity, childhood obesity $^{(15)}$ seems to follow an ethnic, geographic and socio-economic distribution.

The purpose of the current study was to assess the strength of possible risk factors for childhood obesity in a paediatric population from Northern Greece.

\section{Methods}

Four hundred and ten children randomly selected from eight primary and secondary schools from rural and 
urban areas of Thessaloniki, northern Greece, which is a town of about one million people. Randomizations took into consideration the population distribution with regard to age and sex both for urban and rural inhabitants. This procedure was performed by using a computer-assisted method (SPSS statistical software package version 13; SPSS Inc., Chicago, IL, USA). Based on the criteria of the International Obesity Taskforce (IOTF) ${ }^{(16)}, 205$ children were classified as overweight and/or obese (OW/OB; group 1) and were matched with a control group (group 2) of normal-weight children by age and sex. All children were healthy with no history of past disease or taking any medication. Written, informed consent was obtained from the parents of each child who participated in the study. Permission was also obtained from the Ethical Committee of Aristotle University of Thessaloniki, Greece.

All measurements were performed in the morning after overnight fasting by three trained researchers. Body weight was measured to the nearest $0 \cdot 1 \mathrm{~kg}$, with children wearing light clothes and without shoes, using a SECA model 700 scale. Height was measured to the nearest $0 \cdot 1 \mathrm{~cm}$ using a SECA stadiometer. BMI was calculated using the formula [weight $(\mathrm{kg})] /[\text { height }(\mathrm{m})]^{2}$ and children were classified as overweight and obese based on IOTF criteria $^{(16)}$. Body fat percentages were determined by bioelectrical impedance analysis (Maltron BF-906 instrument).

A questionnaire including 145 questions about family history of obesity, duration of breast-feeding, birth weight, physical activity, time sleeping and time watching television was filled in by the participant and one of their parents (mother or father).

Parents reported the time spent by children on leisuretime physical activity. The questionnaire included fifteen activities and ten response categories for frequency, ranging from 'never' to ' $12 \mathrm{~h} /$ week'. A physical activity index was then calculated as the sum of hours spent on strenuous physical activity ${ }^{(17)}$. For each physical activity, a multiple resting metabolic rate (MET score per hour per week) was assigned ${ }^{(18)}$.

A second questionnaire (sixty-five questions) included a validated $\mathrm{FFQ}^{(19)}$ containing 112 food items divided into the following categories: dairy products, meat and eggs, fish, fruits and vegetables, legumes, potatoes and cereals, oils and fat, sweets and sugar-sweetened beverages. Each food item was presented proportionally $(0.5,1,1.5$ portions). The frequency of consumption of any food item was categorized as 1 to $7 \mathrm{~d} /$ week, 1 to $2 \mathrm{~d} /$ month or never.

\section{Statistical analyses}

All data were analysed using SPSS version 13. Descriptive data are reported as means with their standard errors. To compare the characteristics for each group we used the $\chi^{2}$ test for frequencies and the $t$ test for means. For non-parametric data we used the Mann-Whitney $U$ test. Conditional logistic regression was used to estimate the relationship of risk factors to overweight and obesity. Values with $P<0 \cdot 05$ were considered statistically significant.

\section{Results}

Overweight and obese children were classified as one group (OW/OB). Table 1 presents the anthropometric, family and lifestyle characteristics of the OW/OB and control groups. Weight, BMI and percentage body fat were higher in the OW/OB group compared with the control group. OW/OB children watched more television and exercised less compared with the control group.

Table 2 shows the age distribution of the overweight, obese and normal-weight children. No statistically significant differences were found between boys and girls.

Table 1 Demographic, anthropometric and lifestyle characteristics of the study subjects: children randomly selected from eight primary and secondary schools from rural and urban areas of Thessaloniki, northern Greece

\begin{tabular}{|c|c|c|c|c|c|}
\hline & \multicolumn{2}{|c|}{ OW/OB (n 205) } & \multicolumn{2}{|c|}{ Control (n 205) } & \multirow[b]{2}{*}{$P$ valuet } \\
\hline & Mean, $\%$ or $n$ & SE & Mean, $\%$ or $n$ & SE & \\
\hline Age (years) & $11 \cdot 2$ & $3 \cdot 2$ & $11 \cdot 1$ & $3 \cdot 5$ & 0.77 \\
\hline Male (\%) & 48 & & 48 & & 0.86 \\
\hline Height (m) & $1 \cdot 48$ & $7 \cdot 4$ & $1 \cdot 49$ & $6 \cdot 8$ & $0 \cdot 41$ \\
\hline Weight (kg) & 61 & $6 \cdot 2$ & 48 & $5 \cdot 4$ & $0 \cdot 001^{*}$ \\
\hline $\operatorname{BMI}\left(\mathrm{kg} / \mathrm{m}^{2}\right)$ & 25 & $2 \cdot 4$ & 20 & $1 \cdot 9$ & $0.001^{*}$ \\
\hline Body fat (\%) & 36 & $2 \cdot 1$ & $20 \cdot 3$ & $2 \cdot 2$ & $0 \cdot 001^{*}$ \\
\hline Family history of obesity (\%) & 42 & & 11 & & $0 \cdot 001^{*}$ \\
\hline Breast feeding $\geq 3$ months $(n)$ & 16 & & 48 & & $0.001^{*}$ \\
\hline Birth weight $<2 \cdot 8 \mathrm{~kg}(n)$ & 32 & & 27 & & 0.49 \\
\hline Leisure-time physical activity (MET $\times$ h/week) & 24 & $1 \cdot 8$ & 42 & $2 \cdot 4$ & $0 \cdot 001^{*}$ \\
\hline Sleep $(h / d)$ & $9 \cdot 4$ & $1 \cdot 1$ & $9 \cdot 2$ & 0.5 & 0.52 \\
\hline Watching television (h/week) & 17 & 0.5 & 12 & 0.6 & $0 \cdot 001^{*}$ \\
\hline
\end{tabular}

OW, overweight; OB, obese; MET, metabolic equivalent task.

Data are expressed as mean and its standard error, percentage or number of subjects.

${ }^{*}$ Statistically significant difference $(P<0.05)$.

$+P$ value was calculated by Student's $t$ test (parametric distribution), the Mann-Whitney $U$ test (non-parametric distribution) or the $\chi^{2}$ test (frequencies). 
Table 2 Age distribution of overweight (OW), obesity (OB) and normal weight (N) among the study subjects: children randomly selected from eight primary and secondary schools from rural and urban areas of Thessaloniki, northern Greece

\begin{tabular}{|c|c|c|c|c|c|c|c|c|c|c|c|c|}
\hline \multirow[b]{3}{*}{ Age (years) } & \multicolumn{6}{|c|}{ Boys } & \multicolumn{6}{|c|}{ Girls } \\
\hline & \multicolumn{2}{|c|}{ OW $(n 57)$} & \multicolumn{2}{|c|}{$\mathrm{OB}(n 42)$} & \multicolumn{2}{|c|}{$\mathrm{N}(n 99)$} & \multicolumn{2}{|c|}{ OW $(n 58)$} & \multicolumn{2}{|c|}{$\mathrm{OB}(n 48)$} & \multicolumn{2}{|c|}{$\mathrm{N}(n 106)$} \\
\hline & $n$ & $\%$ & $n$ & $\%$ & $n$ & $\%$ & $n$ & $\%$ & $n$ & $\%$ & $n$ & $\%$ \\
\hline 7 & 5 & $8 \cdot 7$ & 3 & $7 \cdot 1$ & 7 & $7 \cdot 1$ & 6 & $10 \cdot 3$ & 4 & $8 \cdot 3$ & 10 & $9 \cdot 4$ \\
\hline 8 & 6 & $10 \cdot 5$ & 2 & $4 \cdot 7$ & 9 & $9 \cdot 1$ & 7 & $12 \cdot 1$ & 4 & $8 \cdot 3$ & 11 & $10 \cdot 4$ \\
\hline 9 & 7 & $12 \cdot 3$ & 3 & $7 \cdot 1$ & 9 & $9 \cdot 1$ & 6 & $10 \cdot 3$ & 5 & $10 \cdot 4$ & 11 & $10 \cdot 4$ \\
\hline 10 & 7 & $12 \cdot 3$ & 3 & $7 \cdot 1$ & 10 & $10 \cdot 1$ & 7 & $12 \cdot 1$ & 7 & 14.5 & 12 & $11 \cdot 3$ \\
\hline 11 & 8 & 14.0 & 7 & $16 \cdot 6$ & 17 & $17 \cdot 2$ & 8 & $13 \cdot 7$ & 6 & 12.5 & 12 & $11 \cdot 3$ \\
\hline 12 & 9 & $15 \cdot 8$ & 10 & $23 \cdot 8$ & 17 & $17 \cdot 2$ & 9 & $15 \cdot 5$ & 7 & $14 \cdot 5$ & 12 & $11 \cdot 3$ \\
\hline 13 & 6 & 10.5 & 5 & 11.9 & 10 & $10 \cdot 1$ & 6 & $10 \cdot 3$ & 5 & $10 \cdot 4$ & 12 & $11 \cdot 3$ \\
\hline 14 & 4 & $7 \cdot 0$ & 5 & 11.9 & 10 & $10 \cdot 1$ & 5 & $8 \cdot 6$ & 5 & $10 \cdot 4$ & 13 & $12 \cdot 3$ \\
\hline 15 & 5 & $8 \cdot 7$ & 4 & 9.5 & 10 & $10 \cdot 1$ & 4 & $6 \cdot 8$ & 5 & $10 \cdot 4$ & 13 & $12 \cdot 3$ \\
\hline
\end{tabular}

$\chi^{2}$ test for differences between genders: $\chi^{2}=1 \cdot 4, P=0.528$.

Table 3 Odds for overweight/obesity (univariate conditional logistic regression model) among the study subjects: children randomly selected from eight primary and secondary schools from rural and urban areas of Thessaloniki, northern Greece

\begin{tabular}{lccl}
\hline & OR & $95 \% \mathrm{Cl}$ & $P$ value \\
\hline Low birth weight $(<2 \cdot 8 \mathrm{~kg})$ & 1.39 & $0.58,1.59$ & 0.68 \\
Breast-feeding $(\geq 3$ months) & 0.88 & $0.63,0.97$ & $0.001^{*}$ \\
Family history of obesity & 4.08 & $2.52,8.83$ & $0.001^{*}$ \\
Leisure-time physical activity & 0.87 & $0.85,0.89$ & $0.001^{*}$ \\
$\quad(M E T \times \mathrm{h} /$ week) & & & \\
Sleep $(\mathrm{h} / \mathrm{d})$ & 1.12 & $0.90,1.31$ & 0.59 \\
Watching television $(14 \mathrm{~h} /$ week $)$ & 1.78 & $1.23,2.65$ & $0.001^{*}$
\end{tabular}

MET, metabolic equivalent task.

${ }^{*}$ Statistically significant $(P<0.05)$.

Table 4 Odds for overweight/obesity associated with food intaket (univariate conditional logistic regression model) among the study subjects: children randomly selected from eight primary and secondary schools from rural and urban areas of Thessaloniki, northern Greece

\begin{tabular}{lccl}
\hline Servings/d & OR & $95 \% \mathrm{Cl}$ & $P$ value \\
\hline Meat and eggs & 1.41 & $0.62,1.66$ & 0.71 \\
Fish & 0.42 & $0.11,0.59$ & 0.53 \\
Dairy products & 1.24 & $0.88,1.39$ & 0.29 \\
Fruits and vegetables & 0.87 & $0.65,1.11$ & $0.001^{*}$ \\
Legumes & 4.20 & $1.40,6.90$ & 0.23 \\
Cereals & 0.76 & $0.62,0.89$ & 0.59 \\
Oils and fats & 1.21 & $0.81,1.44$ & 0.72 \\
Sweets & 0.94 & $0.72,1.38$ & 0.06 \\
Sugar-sweetened beverages & 1.92 & $1.21,2.78$ & $0.001^{*}$ \\
\hline
\end{tabular}

*Statistically significant $(P<0.05)$.

tAdjusted for energy intake.

Table 3 presents the variables (not related to food intake) associated with overweight/obesity in a univariate model. Breast-feeding duration, a family history of obesity, leisure-time physical activity and watching television were significantly associated with overweight/ obesity.

The association of food intake variables with overweight/obesity in a univariate model is shown in Table 4. Consumption of sugar-sweetened beverages was found
Table 5 Multivariate logistic regression analysis of risk factors for overweight/obesity among the study subjects: children randomly selected from eight primary and secondary schools from rural and urban areas of Thessaloniki, northern Greece

\begin{tabular}{lccc}
\hline Variable & OR & $95 \% \mathrm{Cl}$ & $P$ value \\
\hline Breast-feeding ( $\geq 3$ months) & 0.21 & $0 \cdot 11,0 \cdot 79$ & $0.001^{*}$ \\
Family history of obesity & 3.79 & $2 \cdot 61,4 \cdot 18$ & $0.001^{*}$ \\
Leisure-time physical activity & 0.87 & $0.85,0.89$ & $0.001^{*}$ \\
$\quad$ MET $\times$ h/week) & & & \\
Fruits and vegetables & 0.94 & $0.90,1 \cdot 17$ & 0.59 \\
Sugar-sweetened beverages & 1.77 & $1.03,2 \cdot 76$ & $0.001^{*}$ \\
Watching television (h/week) & 1.99 & $1.54,2 \cdot 76$ & $0.04^{*}$
\end{tabular}

*Statistically significant $(P<0.05)$.

to be associated with overweight/obesity. Seventy-three per cent of the OW/OB group consumed $>4$ beverages per week.

Variables that showed a statistically significant difference in OR for overweight/obesity were introduced in a final multivariate model (Table 5). Family history of obesity, watching television and consumption of sugarsweetened beverages were found to be risk factors for overweight/obesity while duration of breast-feeding and leisure-time physical activity were found to be protective factors.

\section{Discussion}

The results of our study indicated that duration of breastfeeding and leisure-time physical activity were protective factors against obesity, while a family history of obesity, sugar-sweetened beverage consumption and watching television were risk factors for developing obesity.

Our study showed that breast-feeding for $\geq 3$ months is a protective factor against obesity. Similar studies have also found the same relationship. In a systematic review by Arenz et $a l^{(20)}$ which included 69000 participants, the authors concluded that breast-feeding has a small, consistent, protective effect against obesity. More recently 
O'Tierney et al. ${ }^{(21)}$ reported that breast-feeding for $<2$ months might be deleterious and was associated with increased BMI. In another study, Moschonis et al. ${ }^{(10)}$ examined the effects of breast feeding on obesity in 2374 Greek children aged 1-5 years, concluding that children who were exclusively breast-fed were 0.49 and 0.54 times less likely to be overweight at 6 and 12 months of age, respectively, than children who were exclusively formula-fed. In contrast, several studies have found that breast-feeding does not seem to protect against obesity in children ${ }^{(9,22)}$. On the other hand, in a recent review Koletzko et al. ${ }^{(23)}$ reported that formula feeding also seems to play an important role in developing obesity since the higher protein content included in the bottle has been found to be positively associated with excess weight in later life. More studies are needed in order to clarify this issue.

Leisure-time activity was a protective factor in our study. Studies performed recently in Greek, Spanish and Swedish populations also have found similar results $^{(9,24,25)}$. Christodoulos et al. ${ }^{(25)}$ examined obesity and parameters of physical fitness in 178 elementaryschool children during an academic year as well as after the summer holidays; they showed significant physical fitness improvements during the school year, with little or no changes in the summer holidays. The authors concluded that children who reported $30 \mathrm{~min}$ of daily participation in physical activity demonstrated lower prevalence rates for overweight and obesity as well as superior fitness performance.

One of the major risks for obesity was found to be family history of obesity in our results. Parental obesity has been also found by others in Greece to be positively associated with child obesity ${ }^{(5)}$. Investigators from other countries have also reached in the same conclusion, that a family history of obesity together with environment and genetics play important roles in the development of childhood obesity ${ }^{(9,25,26)}$.

We found that watching television was also associated with obesity in our subjects. Watching television is a sedentary behaviour which is related to the consumption of unhealthy foods and has been found by many authors as a risk factor for obesity ${ }^{(4,7,9)}$. Manios et al. $^{(7)}$ found in 198 Greek children that overweight/obesity is indicative of an unfavourable lipid profile as well as less physical activity and more watching television.

Although obesity results from an imbalance of energy homeostasis, the true mechanisms underlying this process remain unknown. It has been suggested that intake of sugar-sweetened beverages may promote weight gain and obesity by increasing overall energy intake ${ }^{(27)}$. Currently, sugared soft drinks contribute about 9\% of total energy intake in both children and adults ${ }^{(28)}$. In a recent review, Malik et al. ${ }^{(29)}$ concluded there is strong evidence that sugar-sweetened beverage consumption promotes weight gain and obesity in children and adolescents. In our study we found that consumption of sugar-sweetened beverages was associated with increased risk of obesity.

A limitation of our study is that we did not take in consideration the Tanner stage of each child, or the socioeconomic status and educational level of parents. Another limitation is that since the study was cross-sectional, no cause-and-effect relationships could be established.

\section{Conclusions}

Our results suggest that breast-feeding duration $(\geq 3$ months) and leisure-time physical activity are protective factors against obesity, whereas family history of obesity, watching television and sugar-sweetened beverage consumption positively influence the development of obesity in Greek children.

\section{Acknowledgements}

This research received no specific grant from any funding agency in the public, commercial or not-for-profit sector. None of the other has any conflict of interest. All authors have contributed equally and are in agreement with the content of the manuscript. D.P. organized and collected the data and wrote the paper; P.M. analysed the data and performed the statistical analysis; I.R. supervised the whole procedure.

\section{References}

1. Must A (1996) Morbidity and mortality associated with elevated body weight in children and adolescents. Am J Clin Nutr 63, 3 Suppl., 445S-447S.

2. Kapantais E, Haralambides V, Tzotzas T et al. (2000) First national epidemiological large scale survey on the prevalence of childhood and adolescent obesity in Greece. Int J Obes Relat Metab Disord 28, Suppl. 1, 71.

3. Magkos F, Manios Y, Christakis G et al. (2006) Agedependent changes in body size of Greek boys from 1982 to 2002. Obesity (Silver Spring) 14, 289-294.

4. Manios Y, Kourlaba G, Kondaki K et al. (2009) Obesity and television watching in preschoolers in Greece: the GENESIS study. Obesity (Silver Spring) 17, 2047-2053.

5. Malindretos P, Doumpali E, Mouselimi M et al. (2009) Childhood and parental obesity in the poorest district of Greece. Hippokratia 13, 46-49.

6. Linardakis M, Sarri K, Pateraki MS et al. (2008) Sugar-added beverages consumption among kindergarten children of Crete: effects on nutritional status and risk of obesity. $B M C$ Public Health 8, 279.

7. Manios Y, Yiannakouris N, Papoutsakis C et al. (2004) Behavioral and physiological indices related to BMI in a cohort of primary schoolchildren in Greece. Am J Hum Biol 16, 639-647.

8. Serra-Majem L, Aranceta Bartrina J, Perez-Rodrigo C et al. (2006) Prevalence and determinants of obesity in Spanish children and young people. Br J Nutr 96, Suppl. 1, S67-S72.

9. Ochoa MC, Moreno-Aliaga MJ, Martinez-Gonzalez MA et al. (2007) Predictor factors for childhood obesity in a Spanish case-control study. Nutrition 23, 379-384. 
10. Moschonis G, Grammatikaki E \& Manios Y (2008) Perinatal predictors of overweight at infancy and preschool childhood: the GENESIS study. Int J Obes (Lond) 32, 39-47.

11. Chimonas ET (2001) The treatment of coronary heart disease: an update. Part 2: Mortality trends and main causes of death in the Greek population. Current Med Res Opin 17, 27-33.

12. Mavrakanas TA, Konsoula G, Patsonis I et al. (2009) Childhood obesity and elevated blood pressure in a rural population of northern Greece. Rural Remote Health 9, 1150.

13. Freedman DS, Khan LK, Serdula MK et al. (2004) Inter relationships among childhood BMI, childhood height, and adult obesity: the Bogalusa Heart Study. Int J Obes Relat Metab Disord 28, 10-16.

14. Nieto FJ, Szklo M \& Comstock GW (1992) Childhood weight and growth rate as predictors of adult mortality. $\mathrm{Am}$ J Epidemiol 136, 201-213.

15. Manios Y, Panagiotakos DB, Pitsavos C et al. (2005) Implication of socio-economic status on the prevalence of overweight and obesity in Greek adults: the ATTICA study. Health Policy 74, 224-232.

16. Cole TJ, Bellizzi CM, Flegal MK et al. (2000) Establishing a standard definition for child overweight and obesity worldwide: international survey. BMJ 320, 1240-1243.

17. Manios Y, Kafatos A \& Markakis G (1998) Physical activity in 6-year-old children: validation of two proxy reports. Pediatr Exerc Sci 10, 176-188.

18. Ainsworth B, Haskell W, Whitt M et al. (2000) Compendium of physical activities: an update of activity codes and MET intensities. Med Sci Sports Exerc 32, 9 Suppl., S498-S504.

19. Roumelioti M \& Leotsinidis M (2009) Relative validity of a semiquantitative food frequency questionnaire designed for schoolchildren in western Greece. Nutr $J \mathbf{8}, 8$.
20. Arenz S, Ruckerl R, Koletzko B et al. (2004) Breast-feeding and childhood obesity - a systematic review. Int J Obes Relat Metab Disord 28, 1247-1256.

21. O'Tierney PF, Barker DJ, Osmond C et al. (2009) Duration of breast-feeding and adiposity in adult life. J Nutr 139, 422S-425S.

22. Huus K, Ludvigsson JF, Enskar K et al. (2008) Exclusive breast-feeding of Swedish children and its possible influence on the development of obesity: a prospective cohort study. BMC Pediatr 8, 42.

23. Koletzko B, von Kries R, Monasterolo RC et al. (2009) Infant feeding and later obesity risk. Adv Exp Med Biol 646, $15-29$.

24. Ruiz JR, Rizzo NS, Hurtig-Wennlof A et al. (2006) Relations of total physical activity and intensity to fitness and fatness in children: the European Youth Heart Study. Am J Clin Nutr 84, 299-303.

25. Christodoulos AD, Flouris AD \& Tokmakidis SP (2006) Obesity and physical fitness of pre-adolescent children during the academic year and the summer period: effects of organized physical activity. J Child Health Care 10, 199-212.

26. Reilly JJ, Armstrong J, Dorosty AR et al. (2005) Early life risk factors for obesity in childhood: cohort study. BMJ 330, 1357.

27. Padez C, Mourao I, Moreira P et al. (2005) Prevalence and risk factors for overweight and obesity in Portuguese children. Acta Paediatr 94, 1550-1557.

28. Nielsen SJ \& Popkin BM (2005) Changes in beverage intake between 1977 and 2001. Am J Prev Med 27, 205-210.

29. Malik VS, Schulze MB \& Hu FB (2006) Intake of sugarsweetened beverages and weight gain: a systematic review. Am J Clin Nutr 84, 274-288. 